\title{
Management of acromegaly
}

\author{
J. D. N. NABARRO \\ From the Middlesex Hospital, London W1
}

Consideration of the management of a condition like acromegaly necessitates some understanding of its clinical features and natural history. What follows is based on experience with 150 patients seen at the Middlesex Hospital since 1966, when a satisfactory radioimmunoassay of growth hormone was developed (Jacobs, 1969).

\section{Clinical features}

\section{PRESENTATION}

It is interesting and often instructive to review the way in which patients first presented to their doctor (Table 1). In over one-third of the cases acromegaly was an accidental observation when the patient went to the doctor for some other condition. Surprisingly, less than $10 \%$ of the patients went actually complaining of a change in their appearance, but this reflects the very slow way in which the condition usually evolves. Most of the other presenting symptoms were due to local spread of the tumour or to recognised features or complications of acromegaly, although some were a little unusual-namely, presentation with hirsutism, goitre, nose blocked by nasal polyps, or hemiplegia due to upward extension of the tumour.

\begin{tabular}{lc}
\hline Mode of presentation & No. of patients \\
\hline Accidental observation & 57 \\
Amenorrhoea & 14 \\
Change in appearance & 14 \\
Headache & 14 \\
Carpal tunnel syndrome & 12 \\
Diabetes mellitus & 12 \\
Gigantism & 4 \\
Loss of libido & 4 \\
Hirsutism & 3 \\
Heart failure & 3 \\
Osteoarthritis & 3 \\
Visual field defect & 3 \\
Sweating & 2 \\
Goitre & 2 \\
Blocked nose & 1 \\
Hemiplegia & 1 \\
Cardiomegaly (MMR) & 1 \\
Total & 150 \\
\hline
\end{tabular}

Table 1 Mode of presentation to doctor of 150 patients with acromegaly
In this series of patients I have tried to date the age $\overrightarrow{\vec{\omega}}$ of onset of the first clinical features, although this is notoriously difficult, partly from looking at old?

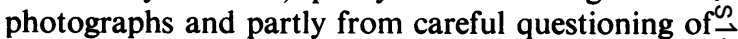
the patients. The results are shown in Table 2. This. was extended further to try to determine the delay $\overrightarrow{ }$ between the onset of the first symptoms and the ${ }^{N}$ diagnosis being made (Table 3). In most cases the diagnosis was made relatively quickly, but in $10^{-}-$ patients it took more than 20 years. The record waso held by an Indian woman whose history dated back? for at least 33 years, but two English patients had a history going back for more than 25 years.

\begin{tabular}{|c|c|c|}
\hline Age (years) & \multicolumn{2}{|c|}{ No. of patiemts } \\
\hline $0-9$ & 3 & \\
\hline $10-19$ & 17 & \\
\hline $20-29$ & 38 & \\
\hline $30-39$ & 43 & \\
\hline $40-49$ & 30 & \\
\hline $50-59$ & 13 & \\
\hline $60-69$ & 6 & \\
\hline Total & 150 & \\
\hline \multicolumn{3}{|c|}{$\begin{array}{l}\text { Table } 2 \text { Age at onset of first clinical change in } 150 \\
\text { patients with acromegaly }\end{array}$} \\
\hline Interval (years) & No. of pa & \\
\hline $0-4$ & 62 & \\
\hline 5- 9 & 40 & \\
\hline $10-14$ & 20 & \\
\hline $15-19$ & 18 & \\
\hline $20+$ & 10 & \\
\hline Total & 150 & \\
\hline
\end{tabular}

Table 3 Interval between first clinical manifestation of $\mathrm{s}$ acromegaly and diagnosis in 150 patients

The more important clinical features of acromegaly which have a bearing on the management of the patient are shown in Table 4. Among the more serious are cardiomegaly, often indicating a cardio? myopathy, and vascular disease which is noto infrequently a cause of death. Hypertension is probably not a complication of acromegaly buf represents the combination of benign essential hyper $\stackrel{\square}{\stackrel{\Phi}{\varrho}}$ 


\begin{tabular}{ll}
\hline Clinical features & No. of patients \\
\hline Diabetes mellitus & 68 \\
Chemical 45 & \\
Clinical 23 & \\
Sweating & 56 \\
Headache & 55 \\
Carpal tunnel symptoms & 35 \\
Hypertension & 33 \\
Amenorrhoea & 23 \\
Cardiomegaly & 17 \\
Vascular disease & 17 \\
Hirsutism & 16 \\
Osteoarthritis & 16 \\
Nasal polyps & 12 \\
Thyroid disease or goitre & 11 \\
Respiratory disease & 6 \\
Impotence & 6 \\
Galactorrhoea & 4 \\
\hline
\end{tabular}

Table 4 Clinical features noted in 150 patients with acromegaly

tension and acromegaly in the same person. However, there seems little doubt that successful treatment of the acromegaly makes it easier to control the hypertension. Among other clinical features noted were pituitary apoplexy in three patients, cutis verticis gyrata $^{1}$ in three, and benign acanthosis nigricans in two.

The occurrence of galactorrhoea in four patients is of some interest. Prolactin levels in patients with acromegaly are raised in $27 \%$ of cases (Franks et al., 1976). In some cases this is due to suprasellar extension of the tumour and interference with the action of prolactin inhibiting factor. In others it is because there is an adenoma which contains two types of cell, one of which secretes growth hormone and the other prolactin (Corenblum et al., 1976). The raised prolactin level is not necessarily associated with galactorrhoea.

\section{NATURAL HISTORY}

Information about the natural history of acromegaly, which has an important bearing on the management of patients, is incomplete. Wright et al. (1970b) retrospectively surveyed 194 patients who had attended a number of centres in London between 1939 and 1967 . They reported that total deaths were twice the expected number, especially in the patients over 45 years of age, and exceeded that expected in relation to cardiac, respiratory, and cerebrovascular disorders. Mortality was also increased in patients with clinical diabetes. The present series has not been followed long enough to produce any meaningful findings about increased mortality. The length of the history in some of the patients suggests that acromegaly may be a relatively benign disease. Neverthe-

${ }^{1}$ Furrowing of the skin of the scalp on the crown and back of the head. less, it seems that untreated acromegaly will ultimately shorten the patient's life. Eighteen patients in this series have died already, from causes shown in Table 5. In addition to those who have died five others have malignant disease-one with carcinoma of the thyroid, three with carcinoma of the breast, and one with carcinoma of the bronchus.

\begin{tabular}{lc}
\hline Cause of death & No. of patients \\
\hline Cardiomyopathy & 3 \\
Cerebrovascular disease & 3 \\
Carcinomatosis, primary breast & 2 \\
Malignant neoplasm in pituitary area after $x$-ray & 2 \\
therapy & \\
Panhypopituitarism after transfrontal surgery; & 1 \\
due to intercurrent illness & 1 \\
Pulmonary embolism after transsphenoidal surgery & 1 \\
Chronic lymphatic leukaemia & 1 \\
Myocated by tongue after fainting & 1 \\
Suicide & 1 \\
Died at home, cause unknown & 2 \\
Total & 18 \\
\hline
\end{tabular}

Table 5 Cause of death in 18 patients with acromegaly

Quite apart from any action in shortening the patient's life the grossly disfiguring changes that may occur have a significant effect on the quality of life, and patients may become unwilling to leave their home because of their facial appearance. One complication that may be very disabling is osteoarthritis, particularly if it affects the hips.

\section{DIAGNOSIS}

Acromegaly is often easy to diagnose on the characteristic facial appearance and the changes in the hands and feet. In milder cases the changes may be subtle and difficult to recognise. The first definitive diagnostic step is to measure the plasma or serum growth hormone level, and this may be done initially in the outpatient department. However, there are many factors-such as stress-which influence growth hormone levels, so it is better to have the patient in hospital for more definite diagnosis and to take the measurements at a consistent time. We take blood first thing in the morning, and have previously shown the variability of the basal growth hormone level in patients with acromegaly (Williams et al., 1975). We therefore recommend at least three morning basal growth hormone measurements before a diagnosis is made.

Occasionally the basal growth hormone level is raised by stress, so that the suppressibility of the raised level by glucose should be studied. If the rise is due to stress it should be suppressed to $<10 \mathrm{mU} / 1$ after $50 \mathrm{~g}$ glucose by mouth. In some patients the severity of the acromegaly may seem disproportionate 
to the level of growth hormone and it may be helpful to measure the 'integrated' growth hormone levels throughout the 24 hours (Daggett, 1976). Discrepancies may remain between the apparent clinical severity and the growth hormone level, and perhaps in these patients the formation of somatomedin in the liver under the influence of growth hormone is either reduced or increased.

The levels of growth hormone in the 150 patients being reviewed are shown in Fig. 1 subdivided according to the treatment given.

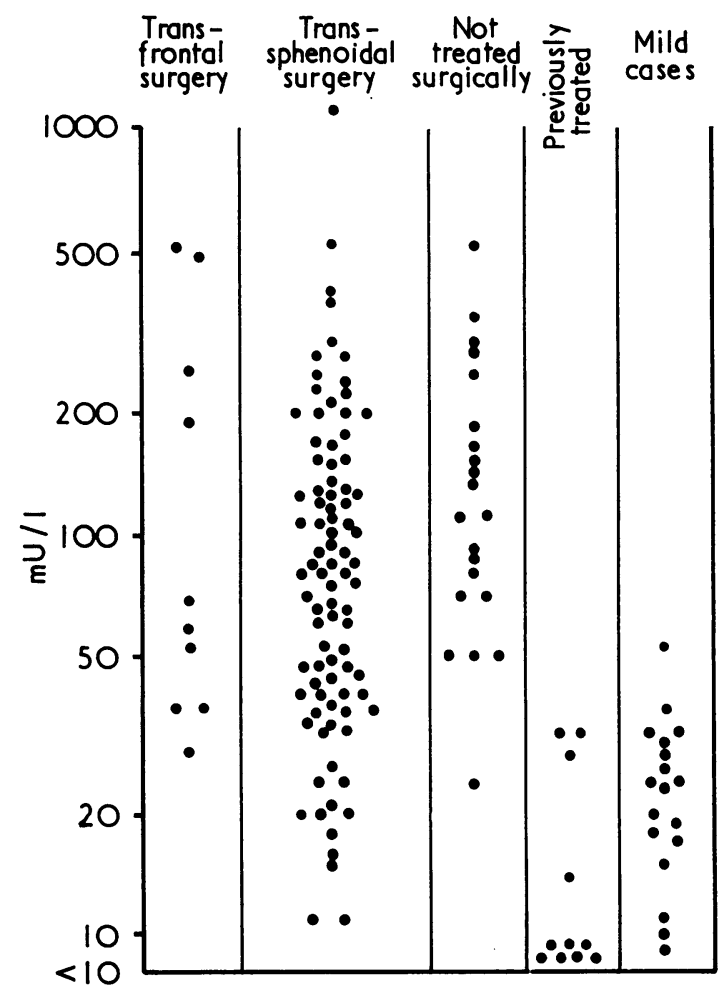

Fig. 1 Mean basal GH levels in 150 patients with acromegaly showing methods of treatment.

The detailed assessment of any patient with acromegaly includes careful clinical examination of the thyroid gland and accurate plotting of the visual fields, chest $x$-ray examination and electrocardiogram to assess the cardiac status, and $x$-ray examination of the skull usually with tomograms and in some cases air-encephalography, arteriography, or both. Metabolic studies include an oral glucose tolerance test with growth hormone measurement. Endocrine assessment before starting treatment should include measurement of the morning and midnight plasma cortisol concentrations, plasma thyroxine and free thyroxine index, and prolactin. In women either a detailed menstrual history or, if $\vec{\sigma}$ postmenopausal, gonadotrophin measurements should be taken. In men plasma testosterone should $\overrightarrow{\vec{F}}$ be measured.

\section{Management of acromegaly}

Clearly, patients with acromegaly, apart from those with the mildest degree of the disease and ${ }^{\infty}$ the smallest rise in growth hormone level, are liable. to develop complications that will shorten their lives. $\overrightarrow{\vec{H}}$ Therefore patients with a considerably raised growth ${ }_{\sigma}^{\omega}$ hormone level and who are not in the 'geriatric' age group should be treated. Suprasellar extension of the $e_{s}$ tumour is an indication for immediate treatment. If complications have already developed, particularly. severe osteoarthritis, vascular disease, or cardio-is myopathy, it seems unlikely that their progress will ${ }_{0}^{N}$ be reversed by lowering the growth hormone level. Other factors to take into consideration are the $\vec{c}_{\vec{C}}$ patient's age, the presence of any intercurrent illness, and, perhaps most important of all, the patient's attitude to his or her disease. Some patients with ${ }^{2}$ quite severe acromegaly have said they would prefer $\vec{\theta}$ to accept the risks and not have any active tref?-के ment, despite careful explanations to them of possible results of lack of treatment.

Three points should be emphasised. Firstly the object of treatment is to reduce growth hormoneo levels to within the normal range without loss of other pituitary trophic hormones. Secondly, if $\mathrm{a}_{\vec{\Omega}}$ patient has a suprasellar extension it is essential to

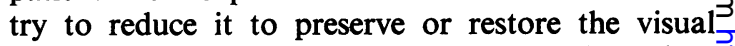
fields. Thirdly, the type of treatment must depend on the expertise and equipment available.

\section{METHODS OF TREATMENT}

Treatments that have been recommended are shown in Table 6. Conventional external irradiation isô widely available but it lowers growth hormone level 3 slowly, and probably in only about half the patients does it reach normal within the first four years (Hunter et al., 1974). Other pituitary hormones are not usually affected by this form of treatment, butr̃ there is a small risk of malignant change in the region? of the pituitary fossa (Table 5). Proton-beam

Conventional external irradiation

Proton-beam irradiation

Interstitial irradiation, "Y Ytrium

Stereotactic cryohypophysectomy

Transfrontal surgery

Transsphenoidal surgery

Bromocriptine

Table 6 Methods of treating patients with acromegaly 
irradiation is not available in Britain. Encouraging results from it have been reported by Kjellberg and Kliman (1973) and Lawrence et al. (1976). Yttrium implantation has been used extensively at the Royal Postgraduate Medical School with a satisfactory reduction in growth hormone level in about $30 \%$ of patients, but a considerable number needed replacement of other pituitary hormones (Wright et al., 1970a). Stereotactic cryohypophysectomy has been used with good results (Lazarus $e t$ al., 1971).

Transfrontal surgery is needed when there is a significant suprasellar extension, particularly with a visual field defect. Ray et al. (1968) reported a series of 24 patients with satisfactory reduction of growth hormone levels in 11 but with quite a number of postoperative complications. Transsphenoidal surgery for pituitary tumours is being developed increasingly (Williams et al., 1975). Hardy (1973) in Montreal has reported that it is possible toremove the pituitary adenoma and leave some normal pituitary in situ.

Bromocriptine is now being used for the treatment of patients with acromegaly and can lower growth hormone levels and ameliorate symptoms. It is ineffective in more severe cases and some patients are reluctant to take tablets indefinitely (Thorner et al., 1975). Somatostatin has been shown to reduce growth hormone levels in patients with acromegaly (Hall et al., 1973), but it has to be given by injection and possibly produces some side effects; it does not seem to be a practical mode of treatment.

\section{TRANSFRONTAL SURGERY}

Ten patients in this series were treated by transfrontal surgery with or without $x$-ray therapy and the results in terms of reduction of growth hormone level have been satisfactory in all except one case. Seven of the patients needed full replacement therapy. One of these unfortunately died of hypopituitarism when he developed a severe gastrointestinal upset and was unable to obtain medical help.

\section{TRANSSPHENOIDAL SURGERY}

This has been the most widely used treatment in the series because of the availability at the Middlesex Hospital of the surgical expertise of Mr R. A. Williams. Eighty-eight patients have been treated in this way and the results in terms of reduction of growth hormone level are shown in Table 7. The mortality and morbidity in these patients was encouraging. One patient died suddenly at home six weeks after operation. Necropsy showed that he had had a pulmonary embolus. Frontal sinusitis has occurred in three patients, transient diabetes

\begin{tabular}{|c|c|c|c|}
\hline \multicolumn{2}{|l|}{ Response to treatment } & \multirow{2}{*}{$\frac{\text { No. }}{63}$} & \multirow{2}{*}{$\frac{(\%)}{(72)}$} \\
\hline Satisfactory & & & \\
\hline $\begin{array}{l}\text { Growth hormone reduced to }<10 \mathrm{mU} / 1 \text { by } \\
\text { operation } \\
\text { Growth hormone reduced to }<10 \mathrm{mU} / 1 \text { by } \\
\text { operation plus } x \text {-ray therapy }\end{array}$ & $\begin{array}{r}60 \\
3\end{array}$ & & (68) \\
\hline $\begin{array}{l}\text { Unsatisfactory } \\
\text { Raised growth hormone level despite } x \text {-ray } \\
\text { therapy after surgery }\end{array}$ & 7 & 25 & $(28$ \\
\hline Total & & 88 & $(100)$ \\
\hline
\end{tabular}

Table 7 Results of transsphenoidal surgery with or without $x$-ray therapy in 88 patients with acromegaly

insipidus in three, and one developed CSF rhinorrhoea which cleared up spontaneously in about 10 days.

The other point of interest is the effect of this operation on other pituitary trophic hormones. The latest endocrine assessment of these 88 patients (Table 8) shows that 51 out of the 63 with a satisfactory response do not require any replacement therapy. Since these patients had often undergone other forms of treatment in the past it is perhaps more important to look at the changes in endocrine status that resulted from transsphenoidal surgery. Of those operated on successfully six lost all their trophic hormones (Table 9) and whereas some lost gonadotrophins others actually regained the ability to secrete them.

\begin{tabular}{lcc}
\hline & Response to treatment \\
\cline { 2 - 3 } & $\begin{array}{l}\text { Satisfactory } \\
(n=63)\end{array}$ & $\begin{array}{c}\text { Unsatisfactory } \\
(n=25)\end{array}$ \\
\hline Mean basal GH after surgery & $\leqslant 10 \mathrm{mU} / 1$ & $>10 \mathrm{mU} / 1$ \\
No replacement therapy & 51 & 13 \\
Gonadotrophin deficient & 17 & 8 \\
Panhypopituitarism & 8 & 10 \\
\hline
\end{tabular}

Table 8 Results of latest endocrine assessment of 88 patients with acromegaly treated by transsphenoidal surgery with or without $x$-ray therapy

$\mathbf{G H}=$ growth hormone.

\begin{tabular}{lcc}
\hline & \multicolumn{2}{c}{ Response to treatment } \\
\cline { 2 - 3 } & $\begin{array}{c}\text { Satisfactory } \\
(n=63)\end{array}$ & $\begin{array}{l}\text { Unsatisfactory } \\
(n=25)\end{array}$ \\
\hline Mean basal GH after treatment & $\leqslant 10 \mathrm{mU} / 1$ & $>10 \mathrm{mU} / 1$ \\
Lost all trophic hormones & 6 & 8 \\
Lost gonadotrophins only & 7 & 2 \\
Regained gonadotrophin & 13 & 3 \\
\hline
\end{tabular}

Table 9 Change in endocrine status of patients with acromegaly after transsphenoidal surgery

$\mathbf{G H}=$ growth hormone. 
There remains the problem of the 25 patients who have failed to respond satisfactorily to transsphenoidal surgery. Ten of them have been treated with deep $x$-ray therapy directed particularly to the region where it was thought that possibly the tumour had not been completely cleared. We are following the growth hormone levels in these patients and have noted that it is lowered to an encouraging extent at the end of the $x$-ray therapy. But the fall is only transient (Fig. 2). Probably it takes some time for the fall to become permanent.

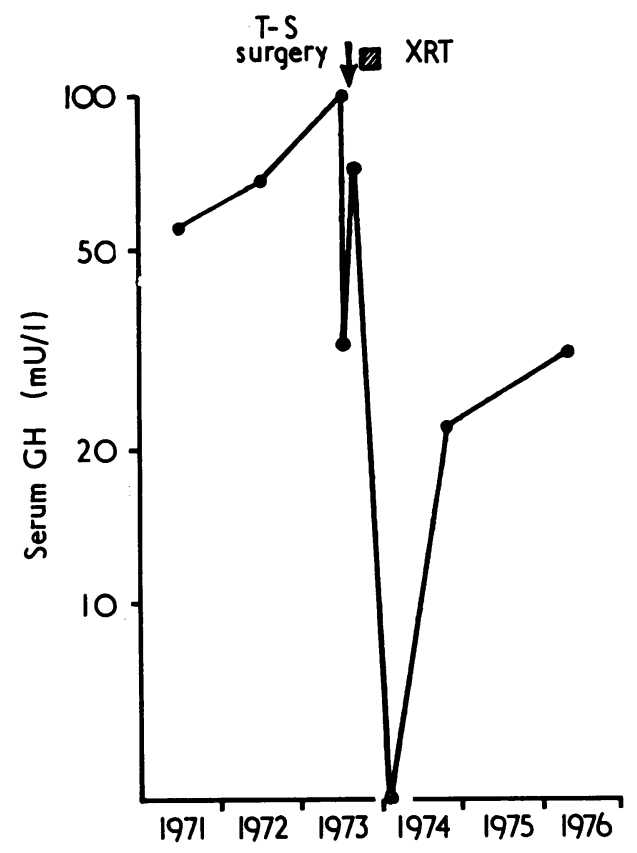

Fig. $2 X$-ray therapy $(X R T)$ in acromegaly showing transient fall in serum growth hormone $(G H)$ immediately after treatment. Patient was a man aged 41.

Some patients had had $x$-ray therapy before undergoing surgery. These cases are rather more difficult to operate on because of the fibrosis and distortion in the pituitary fossa. When the response to operation has not been satisfactory further irradiation has not been given because of the risk of neoplastic change in the area. Seven patients had had yttrium implantation before the operation. This too makes the operation somewhat more difficult on account of fibrosis, but here we have an interesting possibility of a continuing fall in the growth hormone level after the operation as a result of vascular changes induced by the yttrium. This is illustrated by the results in one patient (Fig. 3). Some of the remaining patients have not been treated because four have died (two of them 0 from cardiomyopathy), four have gone abroad, and in another four there were various other reasons.

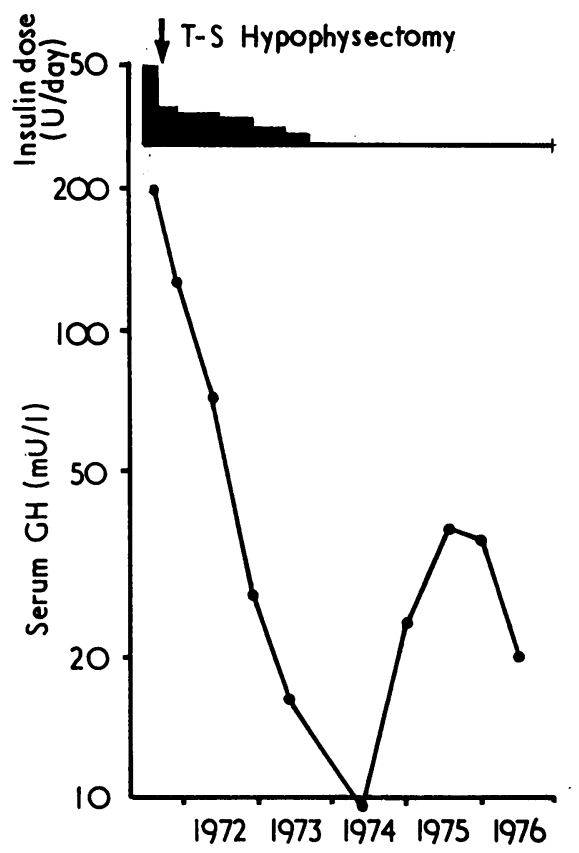

Fig. 3 Transsphenoidal surgery for acromegaly showing continuing fall of growth hormone $(\mathrm{GH})$ level after operation and possible later relapse. Patient was a man aged 36 in 1971; acromegaly diagnosed 1965, yttrium implantation 1968 and 1970.

\section{Other patients}

These included 11 patients who had previously beeni treated with surgery plus $x$-ray therapy (4), with $x$-ray therapy alone (5), or with $x$-ray therapy plus yttrium implantation (2). The last two were referredP on account of a CSF leak which was successfull repaired. Two of these patients were referred when: they had developed neoplastic change in the arew of irradiation.

Four patients were treated with $x$-ray therapy. Twq of these on follow-up show some fall in growth hormone level, but in neither has this reached the normal range. Eight patients have refused any kin $\&$ of treatment. Active therapy was not recommended in nine patients for the following reasons: cardio myopathy in three (of whom two have died) $\frac{0}{0}$ vascular disease in four (of whom three are known to have died), and carcinomatosis in two. Two patient席 
are awaiting treatment. In 18 patients the condition is mild. They are continuing under observation, but four of them are being treated with bromocriptine.

\section{BROMOCRIPTINE}

In 1972 this drug was shown to lower the growth hormone level in patients with acromegaly. This was somewhat surprising because in normal subjects bromocriptine actually raises the level. The fall produced is only modest, but there is often dramatic improvement in the patient's symptoms. In this series bromocriptine has been given to 12 patients. Three of them with cardiomyopathy were regarded as being unfit for surgical treatment. In one the growth hormone level has fallen satisfactorily, but improvement of the cardiomyopathy is difficult to establish. In the other two patients the cardiac failure progressed without any response to bromocripine and they died. Five other patients were given bromocriptine after surgery, with or without $x$-ray thrapy, had failed to lower the growth hormone level to normal. Four of these had a transsphenoidal and one a transfrontal operation. The growth hormone levels in these have fallen but have not yet reached the normal range. Bromocriptine has also been given to four mild cases of acromegaly in whom surgery was not recommended, and in these patients there has been an encouraging fall in growth hormone level. Our experience at present suggests that bromocriptine is not sufficient treatment for patients with high levels of growth hormone but may be used to supplement other treatments. It may also be worth considering in the case of older patients with mild acromegaly.

These patients have been treated in collaboration with Mr R. A. Williams, who performed the transsphenoidal operations. Transfrontal surgery was undertaken by $\mathrm{Mr}$ J. Andrew. The radioimmunoassays were performed by Professor R. P. Ekins and the staff of the Department of Nuclear Medicine of the Middlesex Hospital Medical School. The growth hormone assay was originally set up by Dr H. S. Jacobs. Dr S. Franks performed the prolactin assays, and Dr P. R. Daggett the integrated hormone measurements. I wish also to acknowledge my indebtedness to my registrars and house officers who have helped in the investigation of these patients.

\section{References}

Corenblum, B., Sirek, A. M. T., Horvath, E., Kovacs, K., and Ezrin, C. (1976). Human mixed somatotrophic and lactotrophic pituitary adenomas. Journal of Clinical Endocrinology and Metabolism, 42, 857.

Daggett, P. (1976). A system for the measurement of integrated concentrations of hormones in the blood. Clinical Endocrinology, 5, 595.

Franks, S., Jacobs, H. S., and Nabarro, J. D. N. (1976). Prolactin concentrations in patients with acromegaly. Clinical Endocrinology, 5, 63.

Hall, R., Besser, G. M., Schally, A. V., Coy, D. H., Evered, D., Goldie, D. J., Kastin, A. J., McNeilly, A. S., Mortimer, C. H., Phenekos, C., Tunbridge, W. M. G., and Weightman, D. (1973). Action of growth-hormone-release inhibiting hormone in healthy men and in acromegaly. Lancet, $2,581$.

Hardy, J. (1973). Transsphenoidal surgery for hypersecreting pituitary tumors. Excerpta Medica International Congress Series, 303, 179.

Hunter, W. M., Gillingham, F. J., Harris, P., Kanis, J. A., McGurk, F. M., McLelland, J., and Strong, J. A. (1974). Serial assays of plasma growth hormone in treated and untreated acromegaly. Journal of Endocrinology, 63, 21.

Jacobs, H. S. (1969). Use of activated charcoal in the radioimmunoassay of human growth hormone in plasma. Journal of Clinical Pathology, 22, 710.

Kjellberg, R. N., and Kliman, B. (1973). A system for therapy of pituitary tumors. Excerpta Medica International Congress Series, 303, 234.

Lawrence, J. H., Tobias, C. A., Linfoot, J. A., Born, J. L., and Chong, C. Y. (1976). Heavy-particle therapy in acromegaly and Cushing disease. Journal of the American Medical Association, 235, 2307.

Lazarus, L., Bleasel, K. F., and Connelley, T. J. (1971). Acromegaly treated by cryogenic pituitary destruction. Excerpta Medica International Congress Series, 236, Abstract 146.

Ray, B. S., Horwith, M., and Mautalen, C. (1968). Surgical hypophysectomy as a treatment for acromegaly. In Clinical Endocrinology, Vol. 2, ed E. B. Astwood and C. E. Cassidy, p. 93. New York, Grune and Stratton.

Thorner, M. O., Chait, A., Aitken, M., Benker, G., Bloom, S. R., Mortimer, C. H., Sanders, P., Mason, A. S., and Besser, G. M. (1975). Bromocriptine treatment of acromegaly. British Medical Journal, 1, 299.

Williams, R. A., Jacobs, H. S., Kurtz, A. B., Millar, J. G. B., Oakley, N. W., Spathis, G. S., Sulway, M. J., and Nabarro, J. D. N. (1975). The treatment of acromegaly with special reference to transsphenoidal hypophysectomy. Quarterly Journal of Medicine, 4, 79.

Wright, A. D., Hartog, M., Palter, H., Tevaarwerk, G., Doyle, F. H., Arnot, R., Joplin, G. F., and Fraser, T. R. (1970a). The use of yttrium 90 implantation in the treatment of acromegaly. Proceedings of the Royal Society of Medicine, 63, 221.

Wright, A. D., Hill, D. M., Lowy, C., and Fraser, T. R. (1970b). Mortality in acromegaly. Quarterly Journal of Medicine, 39, 1. 